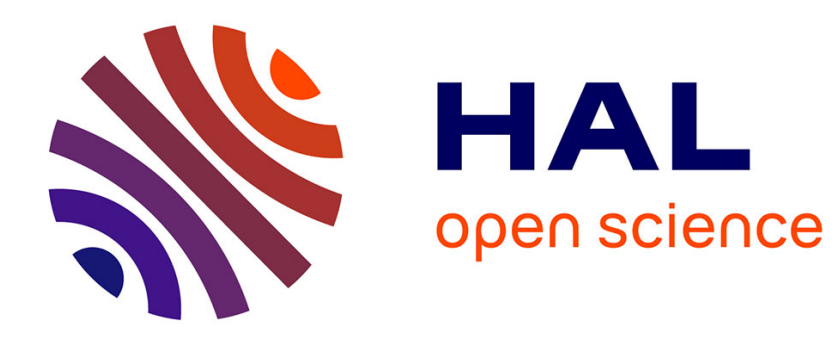

\title{
La culture comme spécialité journalistique
}

William Spano

\section{To cite this version:}

William Spano. La culture comme spécialité journalistique. Le Temps des médias. Revue d'histoire, 2011, 17, pp.164-182. hal-00738288

\section{HAL Id: hal-00738288 \\ https://hal.science/hal-00738288}

Submitted on 3 Oct 2012

HAL is a multi-disciplinary open access archive for the deposit and dissemination of scientific research documents, whether they are published or not. The documents may come from teaching and research institutions in France or abroad, or from public or private research centers.
L'archive ouverte pluridisciplinaire HAL, est destinée au dépôt et à la diffusion de documents scientifiques de niveau recherche, publiés ou non, émanant des établissements d'enseignement et de recherche français ou étrangers, des laboratoires publics ou privés. 
La culture comme spécialité journalistique

Résumé :

A partir d'une approche socio-historique, cet article aborde l'émergence du journalisme culturel en France. En premier lieu, celui-ci propose de revenir sur ce que la presse culturelle doit aux périodiques littéraires des XVIIe et XVIIIe siècles, ainsi qu'aux écrivains et artistes du XIXe siècle. En second lieu, le texte insiste sur l'apparition de regroupements professionnels, impulsés par les membres de la critique artistique, qui vont faire de la culture une spécialité journalistique reconnue durant la première moitié du XXe siècle. Cette recherche s'appuie notamment sur la consultation de différentes éditions de l'Annuaire de la presse française qui a permis de retracer l'évolution professionnelle des représentants de la presse culturelle.

\section{Culture as a Journalism Specialty}

\section{Abstract :}

This paper deals with the emergence of cultural journalism in France based on a socio-historical approach. Firstly we make an account of what the cultural press owes to the literary journals of the $17^{\text {th }}$ and the $18^{\text {th }}$ centuries and to the writers and artists of the $19^{\text {th }}$ century. Secondly, we focus on the emergence of professional structures led by personalities of art criticism which will turn culture into a recognized journalism specialty during the first half of the $20^{\text {th }}$ century. This research is mainly based on data extracted from the various editions of the Annuaire de la presse française which allows us to draw the picture of the professional evolution of cultural press representatives. 


\section{La culture comme spécialité journalistique}

Il est devenu courant de lire des contenus journalistiques placés sous l'intitulé « Culture » dans les titres de la presse française. En effet, la plupart des journaux réservent une partie de leur espace rédactionnel au domaine des productions culturelles, que celui-ci recouvre les différentes formes de spectacles vivants ou bien l'ensemble du secteur des industries culturelles. L'une des caractéristiques majeures du journalisme culturel est même l'élargissement constant de son « champ d'investigation ». En effet, l'extension progressive du contenu des rubriques « Culture » accompagne les changements opérés par le concept de culture à travers I'histoire. Considérée au siècle des Lumières dans une acception humaniste et universaliste, la culture a pris une dimension métaphorique pour désigner le raffinement de l'esprit, nécessaire au progrès de l'Homme. A cette époque, la culture renvoie essentiellement aux domaines de la littérature et des arts grâce auxquels l'esprit de «I'honnête homme » est censé s'élever. L'auteur ou le créateur est placé sur un piédestal, l'acte de création est sacralisé, et la culture noble et légitime est réservée à un cercle restreint d'initiés. Cette conception de la culture traverse les critiques des premiers collaborateurs de presse figurant dans les revues spécialisées et «les journaux d'information générale qui dominent le marché à partir des années $1770 \gg^{1}$. Au cours du XIXe siècle, même si la critique artistique continue à s'adresser en priorité à une élite préoccupée par la question du «Beau », la culture prend une signification plus large ${ }^{2}$. La « culture générale » devient l'affaire de tous et donc un enjeu pour l'éducation. La culture reste néanmoins un outil de distinction sociale, ce que perpétue et renforce le XXe siècle au cours duquel on assiste à une diversification de la notion de culture, marquée par le dynamisme des industries culturelles et le renouvellement continuel des produits qui en sont issus (édition musicale, production cinématographique...) ${ }^{3}$. En effet, les vagues $d$ 'industrialisation et de commercialisation du tournant du $20^{\text {ème }}$ siècle viennent bouleverser tous les secteurs de la vie sociale, y compris celui de la culture. Soumis au développement naissant de la consommation de masse, le domaine culturel connaît des évolutions importantes quant aux pratiques et aux modes de production artistique. De plus, aux différents biens destinés à un public bientôt considéré comme un groupe de consommateurs, s'ajoutent les médias de masse dont les développements techniques semblent assurer une adaptation et un renouveau permanent ${ }^{4}$. Par conséquent, cet élargissement de la notion de culture, né de mutations sociales, politiques, techniques et économiques, affecte la couverture des domaines culturels par les journaux, désireux de suivre les goûts de leurs lecteurs : «De la critique d'art propre à la culture classique et centrée sur la littérature, le théâtre, la musique, la danse et les beaux-arts, le champ de la critique journalistique s'est donc, lui aussi, progressivement diversifié jusqu'à englober les arts nouveaux que sont le cinéma et la vidéo de même que les nombreuses et parfois surprenantes manifestations d'une culture populaire qui était jusqu'alors boudée $\gg^{5}$. Les médias, qui font euxmêmes partie des industries culturelles, participent alors à la diffusion et au renforcement d'une conception devenue marchande de la culture. La spécialité culturelle du journalisme en est à la fois I'une des incarnations et I'un des vecteurs grâce auxquels elle se maintient.

Cette évolution de la rubrique «Culture » dans la presse s'explique donc, en grande partie, par ce que recouvre la notion même de culture (dont nous retraçons ici l'histoire de manière sommaire). Insérés dans la société, les journaux traduisent les changements qui ont marqué celleci au cours du temps. Ceci explique que la stabilisation de la rubrique «Culture » dans l'espace rédactionnel soit tardive. En effet, elle n'est encore que partiellement utilisée dans les années 1980 , et possède, selon les titres, des appellations diverses: «Vie culturelle», «Action culturelle », «Politique culturelle $»^{6}$. Selon Rémy Rieffel et Marie-Françoise Lafosse ${ }^{7}$, les premiers

\footnotetext{
${ }^{1}$ Sgard, J., «La critique est aisée », in Roux, J.-L. (éd.), Critiquer la critique ? Culture et Médias, I'impossible mariage de raison, Ellug, Grenoble, 1994, p. 19.

${ }^{2}$ Nguyên-Duy, V., Cotte, S., «Le journalisme culturel : un défi à l'interprétation paradigmatique des mutations journalistiques », in Rieffel, R. et Watine, T. (ss la dir. de), Les mutations du journalisme en France et au Québec, Editions Panthéon Assas, Paris, 2002, p. 281.

3 Delporte, C., Mollier, J.-Y., Sirinelli, J.-F. (ss la dir. de), Dictionnaire d'histoire culturelle de la France contemporaine, pp. 214-215.

${ }^{4}$ Rioux, J.-P., Sirinelli, J.-F., La culture de masse en France. De la Belle Epoque à aujourd'hui, Hachette Littératures, coll. «Pluriel », Paris, 2002, p. 305.

${ }^{5}$ Nguyên-Duy, V., et alii, ibid, p. 282.

${ }^{6}$ Guyot, B., L'information culturelle, Publications des Langues et des Lettres de Grenoble, Grenoble, 1980, pp. 36-37.
} 
titres fédérant les diverses composantes de la culture sous une appellation commune semblent correspondre aux magazines à partir des années 1950. La presse quotidienne, nationale et régionale, poursuivra globalement le mouvement, à l'image de Libération ou du Monde qui proposeront, à leur tour, des pages «Culture» réunissant différents secteurs et genres rédactionnels. Ainsi, après s'être orientée vers le domaine des arts et des lettres jusqu'au XIXe siècle, I'activité journalistique s'effectue en vertu d'impératifs de consommation au cours du XXe siècle. A partir de l'entre-deux-guerres, la dimension industrielle et marchande de la culture va s'accompagner dans la presse de modes de traitement plus appropriés, comme en témoigne l'essor des rubriques $d^{\prime}$ '« écho » consacrées au milieu culturel et d'information-service, ceci au détriment de la critique classique. Le lecteur est censé privilégier les informations brèves et utiles, susceptibles de l'aider dans ses activités de loisir. Le discours d'information culturelle intègre ces nouvelles prérogatives en minimisant ses engagements -représentés par la critique- au bénéfice de conseils et de recommandations. Les rubriques consacrées aux parutions de disques, de livres ou autres, ainsi que les entretiens menés avec des personnalités marquantes de l'actualité culturelle, incarnent notamment les réponses apportées par la presse au développement d'une consommation culturelle de masse.

Néanmoins, que savons-nous historiquement de la constitution de la culture en spécialité journalistique ? Les recherches socio-historiques portant sur le sujet insistent, d'une part, sur la place déterminante de la critique littéraire et le rôle moteur des écrivains dans les débuts de la presse culturelle au cours des XVIIe, XVIIIe et XIXe siècles ${ }^{8}$; et, d'autre part, sur I'affaiblissement de cette critique sous l'effet de l'adoption par les «professionnels de l'information » de nouveaux genres rédactionnels propres au journalisme dit « d'information » à la fin du XIXe siècle et au début du XXe siècle ${ }^{9}$. Cela dit, comme le remarquait Rémi Rieffel en 2006, « on ne dispose guère [...] d'études sur l'évolution de la critique journalistique au cours de la première moitié du XXe siècle $\gg^{10}$, notamment au niveau socioprofessionnel. En effet, nous possédons peu de données précises sur l'histoire du journalisme culturel et ignorons, en grande partie, la façon dont les représentants de la presse culturelle se sont historiquement structurés pour faire de cette dernière une activité reconnue. Les journalistes culturels se sont-ils constitués en groupe professionnel, comme l'ont fait d'autres corporations journalistiques ? Si tel est le cas, quelles sont les structures qui cristallisent ces regroupements et que représentent-elles par rapport aux autres spécialités journalistiques? Le déclin progressif de la critique se vérifie-t-il dans l'évolution socioprofessionnelle du journalisme culturel ? Ou, au contraire, les représentants de la critique jouent-ils un rôle dans l'affirmation de cette spécialité ?

C'est à cet ensemble de questions que se propose de répondre cet article qui relève les principaux traits saillants de l'évolution de cette spécialité journalistique jusqu'à la seconde guerre mondiale. Après avoir rappelé la genèse de la presse culturelle, nous nous focalisons en particulier sur la situation du journalisme culturel durant la première moitié du XXe siècle car, comme le note Denis Ruellan, la période allant de 1918 à 1940 est le moment où « le groupe des journalistes devient une réalité, au sens où il devient visible, restreint, plus cohérent et surtout reconnu, légitimé à travers un statut ${ }^{11}$. Ainsi, pour comprendre comment le journalisme culturel se structure, il convient de centrer notre attention sur ce tournant majeur de l'histoire du journalisme. Notre entreprise s'appuie sur la consultation de différentes éditions de l'Annuaire de la presse française (fondé en 1879 par M. Mermet), parues dans la première moitié du XXe siècle. Avec un mode d'entrée par journaux, ce recueil annuel a l'avantage de répertorier à la fois les représentants de la presse française, qu'elle soit spécialisée ou généraliste, et les différents regroupements opérés par les journalistes. Nous avons commencé notre consultation de l'Annuaire par l'année 1913 car le début des années 1910 incarne les changements majeurs qu'a connus le journalisme depuis le dernier tiers du XIXe siècle. Comme l'indique Michael Palmer, la période allant de 1863 à 1914 correspond à celle où la presse est un « "mass medium" en gestation »12. L'alphabétisation de la population, I'industrialisation des activités, le mouvement de salarisation

\footnotetext{
7 Lafosse, M.-F., Rieffel, R., «L'évolution du journalisme "culturel". L'exemple de la place et du traitement du spectacle vivant dans la presse écrite française en 1986 et 1996 », in Rieffel, R. et Watine, T. (ss la dir. de), Les mutations du journalisme..., op. cit., 2002, pp. 291-314.

${ }^{8}$ Sgard, J. (ss la dir. de), Dictionnaire des journaux, 1600-1789, Paris, Universitas, 1991 ; Feyel, Gilles, La presse en France, des origines à 1944 - Histoire politique et matérielle, Ellipses, Paris, 1999 ; Ferenczi, T., L'invention du journalisme en France. Naissance de la presse moderne à la fin du $19^{\text {ème }}$ siècle, Plon, Paris, 1993. ${ }^{9}$ Delporte, C., Les journalistes en France 1880-1950, Seuil, Paris, 1999.

10 Rieffel, R., «L'évolution du positionnement intellectuel de la critique culturelle », in Quaderni $n^{\circ} 60$, Ed. Sapienta, Printemps 2006, p. 58.

${ }^{11}$ Ruellan, D., Les « pros » du journalisme. De l'état au statut, la construction d'un espace professionnel, PUR, Coll. «Res Publica », Rennes, 1997, p. 12 (c'est l'auteur qui souligne).

12 Palmer, M., Des petits journaux aux grandes agences. Naissance du journalisme moderne, 1863-1914, Aubier, Paris, 1983.
} 
modifient durablement la presse et la structure sociale du groupe que commencent à former ses représentants à la veille de la première guerre mondiale. Ensuite, nous avons examiné l'Annuaire environ tous les dix ans $(1923,1934)$, en ajoutant une année supplémentaire située à la veille de la seconde guerre mondiale (1939), permettant ainsi de compléter notre bilan ${ }^{13}$. En procédant ainsi, notre enquête permet de suivre le mouvement de professionnalisation des rédacteurs affiliés à des rubriques et journaux culturels.

Dans un premier temps, nous revenons sur la longue histoire du journalisme culturel, de l'esprit critique des premiers périodiques littéraires à l'évolution des modes de traitement de la culture dans les journaux à la fin du XIXe siècle. Dans un second temps, nous présentons les principaux résultats de notre recherche axée sur l'organisation professionnelle de cette spécialité dans la première moitié du XXe siècle.

\section{Un journalisme enraciné dans les périodiques littéraires des XVIIe et XVIIIe siècles}

L'activité qui consiste à traiter du « fait culturel » au sein du journal existe au moins depuis aussi longtemps que des «gens de plume » lisent des livres, assistent à des spectacles ou à des manifestations artistiques, pour en rendre compte ensuite à des lecteurs. C'est donc dans la période au cours de laquelle la presse ne s'adresse qu'à un cercle restreint d'initiés, que nous devons chercher les origines de la spécialité culturelle.

Parmi les titres du XVIIe siècle, Le Journal des Savants et Le Mercure Galant, fondés respectivement en 1665 par Denis de Sallo et en 1672 par Donneau de Vizé, illustrent I'apparition des périodiques dans la presse. Ces deux titres à composante littéraire et théâtrale représentent bien la double tendance d'une presse culturelle naissante, à la fois divertissante et critique puisque ces titres répertorient et apportent de libres commentaires sur les principaux ouvrages imprimés en Europe. Ils cristallisent alors des problématiques qui deviendront récurrentes dans l'univers de la presse et des médias : la liberté contestée de jugement des collaborateurs de presse, le contrôle de l'information par le pouvoir, les relations de connivence... D'autres périodiques du XVIIe siècle, notamment ceux imprimés de l'étranger, ont pour vocation d'indiquer non seulement l'existence d'un livre, mais aussi ses qualités et ses défauts. Les Nouvelles de la République des Lettres (1684) de Pierre Bayle ou plus tard les Essais de littérature pour la connaissance des livres (1702) de I'abbé Tricaud $^{14}$ ne se contentent pas de citer quelques passages des ouvrages parus, mais portent sur eux un jugement d'ordre esthétique, moral, voire idéologique.

En somme, dès le XVIIe siècle, la critique littéraire se fait avec les écrivains, mais aussi contre eux. Avec eux, parce que seules les élites lettrées peuvent avoir les faveurs du pouvoir ou des publicistes pour participer à l'aventure des journaux. Contre eux, parce que les audaces de ces premiers journalistes déplaisent ou mettent en péril l'honorabilité du monde des Lettres. Tantôt soutenue pour sa hardiesse, tantôt discréditée pour son pouvoir de nuisance, la presse littéraire s'enracine dans une activité critique qui se prolongera tout au long du XVIIIe siècle.

Beaucoup d'écrivains des Lumières étaient franchement hostiles à la presse, usant de formules assassines afin de montrer l'infériorité intellectuelle de ses représentants par rapport aux philosophes ${ }^{15}$. Pourtant, même si leur entreprise éditoriale se dirige davantage vers des ouvrages collectifs comme I'Encyclopédie, ces auteurs n'ont jamais refusé d'écrire dans les journaux.

Le XVIIIe siècle est une période où fleurissent un nombre important de périodiques à vocation littéraire et théâtrale. Dans la lignée de ses prédécesseurs, Le Journal de Verdun (1707) ou Le Spectateur français de Marivaux (1721), qui publient aussi des nouvelles politiques, rassemblent extraits de pièces, courts romans, mais aussi comptes rendus, annonces d'événements et réflexions sur la «chose littéraire ». Face à ces journaux, les réactions vont des moqueries à l'interdiction de parution. Ceci n'empêche pourtant pas l'apparition de l'hebdomadaire Le Pour et le Contre que I'Abbé Prévost lance en 1733, ou d'autres titres plus virulents comme les Observations sur les écrits modernes (1735) et de L'Année littéraire $(1754)^{16}$. Leurs deux initiateurs respectifs, I'Abbé Desfontaines et Elie-Jean Fréron, usent d'une plume acérée à l'égard d'ouvrages véhiculant des valeurs contraires à l'ordre moral de l'époque. En effet, Desfontaines et Fréron minimisent les notices bibliographiques et engagent des polémiques. Ils ancrent définitivement les revues littéraires et théâtrales dans une dimension critique, à une époque où celles-ci se multiplient considérablement.

\footnotetext{
13 Naturellement, les années de parution auxquelles nous nous sommes reporté, ont également été conditionnées aux éditions qu'il nous était possible de consulter au cours de notre recherche (certains numéros étaient effectivement introuvables, indisponibles ou en cours de restauration).

${ }^{14}$ Bellanger, C., Godechot, J., Guiral, P. et Terrou, F. (ss la dir. de), Histoire générale de la presse française, PUF, Paris, 1969, tome 1, pp. 143-157.

15 Weil, G., Le Journal, origine, évolution et rôle de la presse périodique, La Renaissance du livre, Coll. «L'évolution de I'Humanité », Paris, 1934.

${ }^{16}$ Bellanger, C. et alii, Histoire générale..., op. cit., 1969, t.1, pp. 259-268.
} 
Ces épisodes où s'opposent les représentants des Arts et des Lettres et ceux de la presse montrent que les motifs de discorde ne sont pas d'une nature strictement littéraire. Les enjeux sont tout autant politiques puisqu'à travers les discussions portant sur la valeur philosophique de tel ou tel ouvrage, ce sont bel et bien des propos politiques qui s'échangent. D'ailleurs, des entrepreneurs de presse anticipent le développement d'une information plus fortement politique, comme l'illustre Le Moniteur universel de Panckoucke en 1789. Après la Révolution, lorsque de nouvelles mesures restrictives sont prises à l'égard de la presse, les revues littéraires retrouvent le rôle qu'elles se sont attribuées sous I'Ancien Régime. S'exprimer sur des questions artistiques, philosophiques ou religieuses permet de contourner le contrôle politique de la presse.

\section{La presse artistique du XIXe siècle : une légitimité issue de sa proximité avec les gens de Lettres}

Le fait que les nouvelles d'ordre culturel soient produites par un cercle relativement restreint de spécialistes, composé à la fois d'hommes de Lettres et d'hommes de presse, est une caractéristique que n'altèrera pas immédiatement le développement des journaux généralistes et populaires du XIXe siècle. A une époque où l'exercice journalistique regroupe des profils extrêmement différents, la presse culturelle se structure à partir des écrivains qui vont lui donner ses lettres de «noblesse journalistique ».

Comme on le sait, écrire dans les gazettes du XIXe siècle ne constitue pas une activité à part entière ${ }^{17}$. L'écriture de presse, telle que la pratiquent les gens de plume, se fait en complément d'une occupation principale qui leur garantit une reconnaissance professionnelle et sociale. La presse joue néanmoins un rôle certain dans leur quête de légitimité, car publier dans les journaux en tant qu'écrivain revient à afficher et à affirmer son existence dans le monde de la littérature. Le détour par les journaux permet de sortir de l'anonymat, voire d'acquérir une certaine notoriété. Pour certains auteurs, l'écriture de presse est un tremplin pour occuper l'espace littéraire qui leur est fermé ${ }^{18}$. Pour d'autres, qui détiennent déjà une position d'autorité dans le milieu littéraire ou artistique, apparaître dans les pages des journaux renforce leur statut de célébrités.

En retour, la présence de ces hommes de Lettres dans la presse d'information culturelle va donner à celle-ci une certaine reconnaissance. L'ouvrage de Thomas Ferenczi atteste des liens unissant le journalisme et la littérature ${ }^{19}$. En effet, l'auteur indique combien la renommée des auteurs de romans, de poésie, de pièces de théâtre, a permis de légitimer certaines rubriques ou genres rédactionnels et, dans une certaine mesure, l'activité journalistique tout entière. Ainsi, parce qu'elle s'apparente peut-être plus que d'autres rubriques à un genre littéraire traditionnellement exercé par des gens de Lettres, la critique artistique suscite des « vocations» auprès des écrivains. Au milieu du XIXe siècle, la publication intitulée l'Artiste, placée sous la direction d'Arsène Houssaye, accueille des critiques nommés Baudelaire, Théophile Gautier ou Stéphane Mallarmé ${ }^{20}$. Dans un article consacré aux critiques de théâtre exerçant leur activité au sortir de l'Empire (1870), Sandrine Anglade note que, parmi les figures de proue de la critique théâtrale, nombreux sont les auteurs dramatiques tels que Catulle-Mendès, Robert de Flers, Edmond Sée ${ }^{21}$. Fidèle à I'héritage que lui ont légué les époques passées, la critique du XIXe siècle est exercée par des écrivains qui vont lui donner une place de choix dans l'espace des journaux. Ils la transformeront en une activité « noble». Par le prestige social de ses représentants, la critique va apparaître comme la forme journalistique qui va légitimer la spécificité culturelle jusqu'à faire de ses représentants, des individus s'apparentant aux figures de l'intellectuel ou de l'artiste engagé ${ }^{22} \ldots$ Les journaux du début du XXe siècle le confirment d'ailleurs puisque, contrairement aux usages en vigueur, les rubriques culturelles seront les seules (avec les éditoriaux) à être régulièrement signées par leurs auteurs ${ }^{23}$. C'est donc parce que certains auteurs tiennent une position élevée dans le milieu culturel, qu'ils vont faire d'une activité d'écriture connue, une pratique journalistique reconnue.

\footnotetext{
${ }^{17}$ Ruellan, D., Le journalisme ou le professionnalisme du flou, PUG, Grenoble, 2007

${ }_{18}$ Bien qu'elle ne traite pas du journalisme culturel mais social, Sandrine Lévêque cite les cas d'André Billy, André Salmon et Max Jacob qui trouvent dans l'écriture de presse un moyen d'investir les mouvements naturaliste (pour le premier) et surréaliste (pour les seconds). Cf. Lévêque, S., Les journalistes sociaux. Histoire et sociologie d'une spécialité journalistique, PUR, Coll. « Res Publica », Rennes, 2000, p. 69.

${ }_{19}$ Ferenczi, T., L'invention du journalisme en France, op. cit., 1993, p. 77.

${ }^{20}$ Bellanger, C. et alii, Histoire générale..., op. cit., t.2, 1969, p. 297.

21 Anglade, S., «Des journalistes au théâtre. Identité professionnelle et espace parisien (1880-1930)》, in

Delporte, C., Médias et ville (XVIIIe - XXe siècle), Université F. Rabelais, Tours, 1997, pp. 137-151.

22 Rieffel, R., «L'évolution du positionnement intellectuel de la critique culturelle», in Quaderni n60, Ed. Sapienta, Printemps 2006, pp. 55-64.

${ }^{23}$ Lévêque, S., Les journalistes sociaux, op. cit., 2000, p. 67.
} 


\section{Le journalisme culturel à l'époque moderne ${ }^{24}$}

Les changements économiques et sociaux du début du XXe siècle favorisent l'émergence des journaux populaires et un renouvellement rédactionnel touchant l'ensemble de la presse, y compris celle spécialisée dans les domaines culturels.

\section{L'évolution de la pratique journalistique}

En premier lieu, la critique connaît des changements importants et durables, décelables à la fin du XIXe siècle. Observant ce qui se passe dans le domaine du théâtre, Christian Delporte constate deux évolutions majeures. La première renvoie à la présence non plus d'un, mais de deux spécialistes de ce sujet au sein du journal. Ainsi, alors que le «courriériste » traite «[d]es nouvelles et [d]es échos des scènes parisiennes », un autre rédacteur perpétue, lui, la tradition de la critique en «livr[ant] des impressions personnelles sur le spectacle». La seconde évolution concerne précisément la nature même de l'exercice critique au cours duquel son représentant «fournit un compte rendu détaillé et documenté de la représentation qui éclaire le lecteur sur son contenu $\gg^{25}$. A présent, le critique se fait surtout le porte-parole des lecteurs, en tentant «de se mettre à [leur] place » et «d'épouser [leurs] façon[s] de voir $»^{26}$.

Parallèlement, les représentations théâtrales, de plus en plus nombreuses, font passer les critiques d'un rythme hebdomadaire (tous les lundis) à un rythme quotidien, ce qui n'est pas, là encore, sans incidence sur leur rédaction. Ces évolutions suscitent, à l'époque, de vifs reproches comme celui de l'appauvrissement de la «qualité littéraire» de la critique. Cette dernière renouvelle son mode de traitement en accordant autant, sinon plus, de place à l'observation et à I'analyse des œuvres qu'à la virtuosité de son style. Le contexte de l'époque, marqué par la diffusion de la presse à un public vaste et moins spécialiste qu'auparavant, est un changement majeur pour les acteurs de la critique. Ceux-ci vont progressivement doter leur activité de normes et de critères visant à détacher la critique de l'exercice surtout littéraire qu'elle incarnait jusque-là.

En second lieu, cette époque correspond à la multiplication des manifestations artistiques et culturelles, et voit apparaître de nouvelles rubriques, élargissant ainsi l'approche rédactionnelle des «événements culturels ». En effet, des formes nouvelles de traitement journalistique vont progressivement prendre place dans les journaux, souvent par l'intermédiaire des quotidiens populaires «à un sou». Ceux-ci accueillent de nouvelles pratiques journalistiques qui gagnent I'ensemble des pages culturelles. Le reportage littéraire et ses différentes déclinaisons que sont I'enquête et l'interview se développent. Ces approches tiennent leurs spécialistes, comme Fernand Xau, réalisant en 1880 pour Le Voltaire (1878), I'un des premiers entretiens dans la presse. Nous trouvons aussi Talmeyr, rédacteur à I'Intransigeant (1880), au Gil Blas (1879), au Figaro (1866 pour sa version quotidienne) et au Gaulois $(1868)^{27}$ ainsi que Jules Huret, signataire d'une enquête concernant le milieu littéraire en $1891^{28}$.

Ces changements dans la presse, qui interviennent sous la Troisième République, marqueront durablement les procédés de réalisation des journaux. Ceux-ci vont être accompagnés d'un discours portant sur les valeurs du métier, favorisant, malgré certaines difficultés ${ }^{29}$, I'affirmation du groupe des journalistes en profession tout au long du XXe siècle. Il s'agit alors d'ériger en référence absolue le journalisme dit «d'information », censé garantir l'objectivité et la transparence des méthodes de travail de ses praticiens. Ceux-ci se présentent alors comme des techniciens de l'information, revendiquant un certain nombre de principes, tels que la hiérarchisation des informations, la séparation du fait et du commentaire, l'imperméabilité avec les autres univers sociaux, le cloisonnement avec les services commerciaux ... Ces règles qui donnent au/du journalisme une vision normative, assez éloignée de la réalité, interviennent dans ce contexte précis où les journalistes entendent affirmer leur identité et revendiquer le monopole de savoir-faire bien établis, les distinguant des hommes de Lettres, très présents dans les colonnes des journaux.

Ce processus touche l'ensemble de la presse et n'épargne donc pas la spécialité culturelle. Le souci pour la profession de trouver une légitimité propre, en prétendant à l'objectivité et au bienfait des techniques « régissant » le traitement des informations, se situe en contradiction avec

\footnotetext{
${ }^{24}$ Le terme «moderne » qualifie la période de la fin du XIXe siècle et du début du XXe siècle, au cours de laquelle la presse connaît une modification durable de ses structures sociales et économiques. Pour avoir une vision plus détaillée de ces éléments: Palmer, M., Des petits journaux aux grandes agences, op., cit., 1983 ; Bautier, R., Cazenave, E., Les origines d'une conception moderne de la communication. Gouverner l'opinion au XIXe siècle, PUG, coll. «La communication en plus », 2000.

25 Delporte, C., Les journalistes en France 1880-1950, op. cit., 1999, p. 58.

${ }^{26}$ Ferenczi, T., L'invention du journalisme..., op. cit., 1993, p. 110.

27 Ferenczi, T., ibid, p. 57 et p. 63.

28 Delporte, C., Les journalistes en France 1880-1950, op. cit., 1999, p. 72.

29 Rieffel, R., «Journalistes : identité et pratiques», in Sfez, L., (ss la dir. de), Dictionnaire critique de la communication, t.2, PUG, 1993, pp. 1021-1022.
} 
le discours des représentants traditionnels des rubriques et journaux culturels. Etant donné que le style de l'auteur et la subjectivité de son regard ne correspondent plus aux valeurs premières de la profession, les acteurs de la presse culturelle tentent de concilier leur héritage avec la nouvelle vision du métier de journaliste et le renouvellement des pratiques, expliquant ainsi la baisse d'influence de la critique dans les journaux. Alors que, pendant longtemps, elle a constitué un point d'ancrage de la profession, la critique se voit mise à distance à mesure que les journalistes souhaitent gagner en autonomie et en légitimité au cours du XXe siècle.

La naissance du journalisme spécialisé dans la culture

Les évolutions que connaît la critique dans le dernier tiers du XIXe siècle ne signifient pas que celle-ci disparaît. En effet, I'histoire qu'entretient la presse avec la critique artistique montre que cette dernière est très présente parmi la profession naissante des journalistes. La consultation des éditions de l'Annuaire de la presse française indique que les rédacteurs en charge de la critique constituent un effectif plus important que celui d'autres spécialités thématiques du journalisme, également en voie de constitution, telles que l'information judiciaire, sportive ou agricole.

Le premier tableau que nous proposons ci-dessous récapitule le nombre de journaux auxquels collaborent des rédacteurs de critiques culturelles (cf. tableau 1). Il indique la place de la critique culturelle dans la presse au cours des premières décennies du XXe siècle ${ }^{30}$. Le second tableau présente le nombre de journaux accueillant des rubriques consacrées à d'autres spécialités thématiques, également présentes dans les journaux de cette époque (cf. tableau 2). La comparaison qui peut être effectuée entre ces dernières et la spécialité culturelle montre la supériorité représentative de la culture sur les autres domaines abordés par la presse.

\begin{tabular}{|c|c|c|c|c|}
\hline \multirow{2}{*}{$\begin{array}{c}\text { Nombre de } \\
\text { journaux } \\
\text { auxquels } \\
\text { collaborent des } \\
\text { rédacteurs de } \\
\text { critique }\end{array}$} & \multicolumn{4}{|c|}{ Années d'édition de I'Annuaire de la presse française } \\
\hline & 1913 & 1923 & 1934 & 1939 \\
\hline musicale & 170 & 129 & 100 & 77 \\
\hline artistique & 132 & 136 & 84 & 82 \\
\hline littéraire ${ }^{31}$ & 144 & 152 & 152 & 124 \\
\hline dramatique $^{32}$ & 203 & 154 & 90 & 113 \\
\hline TOTAL & 649 & 571 & 426 & 396 \\
\hline
\end{tabular}

\section{Tableau 1 : Nombre de journaux du début du XXe siècle auxquels collaborent des} rédacteurs de critique culturelle

Ce tableau a été réalisé en repérant, à partir des listes de «Critiques musicaux, artistiques, littéraires et dramatiques » figurant dans les éditions de 1913, 1923, 1934 et 1939 de l'Annuaire de la presse française, les journaux auxquels ces derniers sont rattachés.

\footnotetext{
${ }^{30}$ Deux remarques doivent être faites : tout d'abord, ce tableau reste perfectible car tous les journaux ne se manifestent pas forcément chaque année auprès de l'Annuaire; ensuite, comme nous ne connaissons pas le nombre total de journaux ayant paru respectivement en $1913,1923,1934$ et 1939, les chiffres que nous indiquons ici trouvent leur intérêt dans leur comparaison avec ceux d'autres spécialités, présentés dans le tableau 2.

${ }^{31}$ Pour les années 1934 et 1939, l'Annuaire classe avec les rédacteurs de critique littéraire ceux de critique dite « historique ».

32 Pour les années 1934 et 1939, l'Annuaire classe avec les rédacteurs de critique dramatique ceux qu'il nomme les « chroniqueurs de cinéma ». Il semble qu'au regard de certains journaux présents, la liste des rédacteurs de critique dramatique de l'année 1923 fasse de même (bien qu'elle ne le mentionne pas).
} 


\begin{tabular}{|c|c|c|c|c|}
\hline $\begin{array}{c}\text { Nombre de } \\
\text { journaux } \\
\text { auxquels } \\
\text { collaborent des } \\
\text { rédacteurs de } \\
\text { chronique }\end{array}$ & $\mathbf{1 9 1 3}$ & $\mathbf{1 9 2 3}$ & $\mathbf{1 9 3 4}$ & $\mathbf{1 9 3 9}$ \\
\cline { 2 - 5 } judiciaire & 84 & 90 & 66 & 50 \\
\hline scientifique 33 & 82 & 78 & 62 & 45 \\
\hline sportive & 76 & 119 & 107 & 98 \\
\hline $\begin{array}{c}\text { parlementaire } \\
\text { j4 }\end{array}$ & 63 & 82 & 75 & 68 \\
\hline $\begin{array}{c}\text { agricole et } \\
\text { horticole }\end{array}$ & -- & -- & 13 & 15 \\
\hline
\end{tabular}

\section{Tableau 2 : Nombre de journaux du début du XXe siècle auxquels collaborent des rédacteurs de chroniques spécialisées}

Ce tableau a été réalisé en repérant, à partir des listes de «Chroniqueurs judiciaires, scientifiques, sportifs, parlementaires et agricoles » figurant dans les éditions de 1913, 1923, 1934 et 1939 de l'Annuaire de la presse française, les journaux auxquels ces derniers sont rattachés (les tirets (--) indiquent qu'aucun chroniqueur n'est répertorié dans l'édition de l'année considérée).

Au-delà de la chute importante et progressive des journaux auxquels collaborent des rédacteurs de critiques et chroniques spécialisées ${ }^{35}$, ce qui frappe, à la lecture de ces tableaux, c'est la prééminence des rédacteurs de critiques culturelles. Les acteurs des autres spécialités que nous trouvons dans l'Annuaire de la presse française sont plus faiblement représentés: par exemple, en 1913, le nombre de journaux accueillant des rédacteurs judiciaires (84), scientifiques (82), sportifs (76) ou parlementaires (63) est sans commune mesure avec celui des titres auxquels collaborent des rédacteurs de critiques musicale (170), artistique (132), littéraire (144) ou dramatique (203). Même s'il connaît quelques variations, cet écart perdure dans les éditions de I'Annuaire de 1923, 1934 et 1939.

L'omniprésence et la régularité des critiques culturelles dans les journaux s'expliquent non seulement par l'ancienneté que possède cette spécialité par rapport aux autres, mais aussi par le contexte du début du XXe siècle. En effet, cette époque est, d'abord, marquée par une vie intellectuelle extrêmement dense, notamment incarnée par la création d'associations régionales ou nationales à caractère idéologique, scientifique, artistique voire professionnelle ou politique. Ces dernières lancent alors de multiples bulletins d'informations, chargés de relayer leurs centres d'intérêt, leurs idées et leurs débats qui tendent à se généraliser à l'ensemble de la presse, à commencer par les journaux populaires. Par exemple, à la suite des revues spécialisées, certains quotidiens créeront des rubriques hebdomadaires consacrées au cinéma ${ }^{36}$. Ensuite, la nature et le nombre des manifestations artistiques augmentent sous la Troisième République. Les expositions, les numéros de cabaret et les représentations théâtrales se développent alors que, parallèlement, la vie des vedettes de cinéma et les films en provenance des Etats-Unis font leur apparition. De ce fait, l'apparition de revues reflétant les préoccupations de bon nombre de «courants socioculturels », ainsi que la prolifération des manifestations artistiques jouent un rôle majeur dans le développement de la presse de cette époque. Ce mouvement intellectuel, qui intervient dans un

\footnotetext{
${ }^{33}$ Pour les années 1934 et 1939, l'Annuaire intègre aux rédacteurs de chronique scientifique, ceux de chronique médicale.

${ }^{34}$ Pour l'année 1939, les rédacteurs de chronique parlementaire se nomment « parlementaires et politiques ».

${ }^{35}$ Cette chute marque, en effet, l'ensemble des spécialités répertoriées. De manière générale, après la première guerre mondiale, et malgré la prospérité des magazines à partir des années 1950, le nombre de journaux (ainsi que leur tirage) baisse sensiblement. Cf. Jeanneney, J.-N., Une histoire des médias, op. cit., 1996, p. 193.

${ }^{36}$ La première apparaîtrait dans Le Gaulois en mars 1916 ; la seconde est tenue, en juin 1918, par Louis Delluc dans Paris-Midi. Cf. Bellanger, C. et alii, Histoire générale..., op. cit., t.3, 1969, p. 480.
} 
climat d'industrialisation et de commercialisation accrues, conduit à multiplier le nombre des journaux et rubriques culturels.

Même si elle ne s'applique pas de la même façon au théâtre, à la littérature ou au cinéma, la critique paraît tellement ancrée dans I'histoire des journaux, qu'elle se présente comme le mode de traitement premier des événements culturels. Mais cette antériorité n'explique qu'en partie sa forte présence dans la presse. En effet, il faut également lui ajouter, au même moment, un autre facteur déterminant : le mouvement de professionnalisation de ses représentants.

Le processus de professionnalisation, qui débute à la fin du XIXe siècle, concerne l'ensemble de la presse. Il va progressivement donner naissance à la profession de journaliste, tel qu'on la connaît aujourd'hui. Certains collaborateurs de presse de cette période vont affirmer leur appartenance à un corps de métier distinct de ceux d'autres acteurs qui remplissent également les colonnes des journaux (ceux que l'on nomme à l'époque les « amateurs », à savoir les écrivains, les professeurs, etc.). Cette prise de conscience n'émerge que parce qu'elle est notamment impulsée par le salariat d'un nombre croissant de rédacteurs : « le sentiment d'avoir un métier spécifique et d'appartenir à un groupe professionnel se construit dans la régularité du travail [et] le nombre de collaborateurs $\gg^{37}$. Ainsi, ces premiers regroupements vont correspondre à la défense d'intérêts collectifs face aux ambiguïtés qui pèsent sur la profession naissante. Ces premières formes de solidarité sont incarnées par les associations professionnelles ${ }^{38}$.

La consultation des éditions de l'Annuaire de la presse française permet de prendre connaissance des différentes structures de solidarité agissant pour le compte des représentants de la presse culturelle. Notre objectif est d'avoir une idée générale, mais suffisamment précise, de ce que celle-ci représente au sein du journalisme naissant. Comme l'Annuaire dresse la liste de l'ensemble des organismes professionnels et syndicaux, généralistes ou spécialisés, de la presse française, nous avons pu répertorier ceux faisant explicitement et exclusivement référence aux domaines culturels tels que la littérature, la musique, le théâtre, les arts... (cf. tableau 3). Là encore, la comparaison avec d'autres domaines tels que l'économie, le sport ou la médecine s'avère instructive (cf. tableau 4).

\footnotetext{
${ }^{37}$ Ruellan, D., Les «Pro » du journalisme, op. cit., 1997, p. 17.

38 Martin, M., Contribution à l'histoire des journalistes et du journalisme (XIXe - XXe siècles) et de la publicité, thèse d'Etat, Université Paris 10-Nanterre, 1992.
} 


\begin{tabular}{|c|c|c|c|c|}
\hline & \multicolumn{4}{|c|}{ Années d'édition de I'Annuaire de la presse française } \\
\hline & 1913 & 1923 & 1934 & 1939 \\
\hline $\begin{array}{c}\text { Nombre } \\
\text { d'associations } \\
\text { professionnelles } \\
\text { et de syndicats } \\
\end{array}$ & 113 & 97 & 129 & 141 \\
\hline $\begin{array}{c}\text { Intitulés des } \\
\text { associations } \\
\text { professionnelles } \\
\text { et des syndicats } \\
\text { faisant référence à } \\
\text { des domaines } \\
\text { culturels }\end{array}$ & $\begin{array}{c}\text { Association de la presse } \\
\text { théâtrale périodique } \\
\text { Association professionnelle des } \\
\text { courriéristes de théâtre des } \\
\text { quotidiens de Paris } \\
\text { Association syndicale des } \\
\text { critiques littéraires et } \\
\text { bibliographes } \\
\text { Syndicat de la presse artistique } \\
\text { Syndicat de la critique } \\
\text { parisienne } \\
\text { Association professionnelle et } \\
\text { mutuelle de la critique } \\
\text { dramatique et musicale }\end{array}$ & $\begin{array}{l}\text { Association de la presse } \\
\text { théâtrale française } \\
\text { Association professionnelle } \\
\text { des courriéristes de théâtre } \\
\text { des quotidiens de Paris } \\
\text { Association professionnelle } \\
\text { et mutuelle de la critique } \\
\text { dramatique et musicale } \\
\text { Association professionnelle } \\
\text { de la presse } \\
\text { cinématographique } \\
\text { Association syndicale de la } \\
\text { critique littéraire } \\
\text { Syndicat de la critique } \\
\text { parisienne } \\
\text { Syndicat français de la } \\
\text { presse d'art et d'érudition } \\
\text { Syndicat de la presse } \\
\text { artistique }\end{array}$ & $\begin{array}{l}\text { Association de la critique } \\
\text { cinématographique } \\
\text { Association professionnelle } \\
\text { et mutuelle de la critique } \\
\text { dramatique et musicale } \\
\text { Association professionnelle } \\
\text { de la presse } \\
\text { cinématographique } \\
\text { Association syndicale de la } \\
\text { critique littéraire } \\
\text { Association syndicale } \\
\text { professionnelle des } \\
\text { journalistes de la radio } \\
\text { Syndicat de la critique } \\
\text { parisienne } \\
\text { Syndicat de la presse } \\
\text { artistique } \\
\text { Syndicat professionnel des } \\
\text { journalistes de la radio }\end{array}$ & $\begin{array}{c}\text { Association de la presse } \\
\text { artistique française } \\
\text { Association professionnelle et } \\
\text { mutuelle de la critique } \\
\text { dramatique et musicale } \\
\text { Association professionnelle de } \\
\text { la presse cinématographique } \\
\text { Association syndicale de la } \\
\text { critique littéraire } \\
\text { Association syndicale } \\
\text { professionnelle des journalistes } \\
\text { de la radio } \\
\text { Chambre syndicale française de } \\
\text { la presse filmée } \\
\text { Syndicat de la critique } \\
\text { parisienne }\end{array}$ \\
\hline Total & 6 & 8 & 8 & 8 \\
\hline
\end{tabular}

Tableau 3 : Liste des associations professionnelles et des syndicats faisant référence aux domaines culturels

Ce tableau a été réalisé en repérant, à partir de l'index des éditions de 1913, 1923, 1934 et 1939 de l'Annuaire de la presse française, les regroupements d'adhérents appartenant à la spécialité culturelle et renvoyant explicitement aux notions de syndicat et de profession (sont donc exclus les sociétés, unions ou autres comités littéraires, dramatiques...). 


\begin{tabular}{|c|c|c|c|c|}
\hline \multirow{2}{*}{$\begin{array}{l}\text { Associations } \\
\text { professionnelles } \\
\text { et syndicats } \\
\text { spécialisés dans }\end{array}$} & \multicolumn{4}{|c|}{ Années d'édition de I'Annuaire de la presse française } \\
\hline & 1913 & 1923 & 1934 & 1939 \\
\hline la justice & $\begin{array}{c}\text { Association confraternelle et } \\
\text { mutuelle de la presse } \\
\text { judiciaire parisienne } \\
\text { Association des informateurs } \\
\text { judiciaires }\end{array}$ & $\begin{array}{c}\text { Association confraternelle et } \\
\text { mutuelle de la presse } \\
\text { judiciaire parisienne } \\
\text { Association des informateurs } \\
\text { judiciaires }\end{array}$ & $\begin{array}{l}\text { Association confraternelle et } \\
\text { mutuelle de la presse } \\
\text { judiciaire parisienne } \\
\text { Association des informateurs } \\
\text { judiciaires }\end{array}$ & $\begin{array}{l}\text { Association confraternelle et } \\
\text { mutuelle de la presse } \\
\text { judiciaire parisienne } \\
\text { Association des informateurs } \\
\text { judiciaires }\end{array}$ \\
\hline la médecine & $\begin{array}{l}\text { Association de la presse } \\
\text { médicale }\end{array}$ & $\begin{array}{l}\text { Association de la presse } \\
\text { médicale }\end{array}$ & $\begin{array}{c}\text { Association de la presse } \\
\text { médicale } \\
\text { Association professionnelle des } \\
\text { journalistes médicaux }\end{array}$ & $\begin{array}{l}\text { Association de la presse } \\
\text { médicale } \\
\text { Syndicat des journalistes } \\
\text { médicaux } \\
\end{array}$ \\
\hline le sport ${ }^{40}$ & $\begin{array}{l}\text { Association des journalistes } \\
\text { sportifs }\end{array}$ & $\begin{array}{l}\text { Association des journalistes } \\
\text { sportifs } \\
\text { Syndicat de la presse sportive }\end{array}$ & $\begin{array}{l}\text { Association des journalistes } \\
\text { sportifs }\end{array}$ & Syndicat de la presse sportive \\
\hline $\begin{array}{c}\text { le domaine } \\
\ll \text { parlementaire }\end{array}$ & $\begin{array}{l}\text { Association syndicale } \\
\text { professionnelle des } \\
\text { journalistes parlementaires }\end{array}$ & $\begin{array}{l}\text { Association syndicale } \\
\text { professionnelle des } \\
\text { journalistes parlementaires }\end{array}$ & $\begin{array}{l}\text { Association syndicale } \\
\text { professionnelle des } \\
\text { journalistes parlementaires }\end{array}$ & $\begin{array}{l}\text { Association syndicale } \\
\text { professionnelle des } \\
\text { journalistes parlementaires }\end{array}$ \\
\hline $\begin{array}{l}\text { l'économie et les } \\
\text { finances }\end{array}$ & $\begin{array}{l}\text { Association des journalistes } \\
\text { financiers } \\
\text { Association de la presse } \\
\text { économique et financière }\end{array}$ & $\begin{array}{l}\text { Association de la presse } \\
\text { économique et financière }\end{array}$ & $\begin{array}{l}\text { Association des journalistes } \\
\text { financiers } \\
\text { Association de la presse } \\
\text { économique et financière }\end{array}$ & $\begin{array}{c}\text { Association des journalistes } \\
\text { financiers } \\
\text { Association syndicale de la } \\
\text { presse économique et } \\
\text { financière } \\
\end{array}$ \\
\hline I'agriculture & -- & $\begin{array}{l}\text { Association de la presse } \\
\text { agricole }\end{array}$ & $\begin{array}{c}\text { Association de la presse } \\
\text { agricole } \\
\text { Syndicat national des journaux } \\
\text { agricoles } \\
\end{array}$ & $\begin{array}{l}\text { Association de la presse } \\
\text { agricole }\end{array}$ \\
\hline
\end{tabular}

Tableau 4 : Liste des associations professionnelles et syndicats faisant référence à d'autres spécialités thématiques abordées dans la presse

Ce tableau a été réalisé en repérant, à partir de l'index des éditions de 1913, 1923, 1934 et 1939 de l'Annuaire de la presse française, les regroupements d'adhérents appartenant à des spécialités autres que culturelles et renvoyant explicitement aux notions de syndicat et de profession (les tirets (--) indiquent qu'aucun regroupement n'est répertorié à l'année considérée).

${ }^{39}$ Cette association regroupe des membres honoraires (magistrats, avocats...) ainsi que des « sociétaires participants », c'est-à-dire des journalistes.
40 Pour la presse de sport, il est aussi référencé un syndicat patronal, le Syndicat des directeurs de journaux sportifs (dans les quatre éditions analysées) 
Sur un plan général, la consultation de l'Annuaire indique une hausse constante des organisations professionnelles dans la première moitié du XXe siècle (à l'exception de la période suivant la première guerre mondiale). Certaines peuvent disparaître, pour parfois réapparaître ou être remplacées, alors que d'autres persistent au fil des années, mais globalement leur nombre est en progression. Parmi ces organisations, nous notons la présence à la fois d'associations professionnelles constituées à la fin du siècle dernier et d'organismes syndicaux créés dans le sillage de la première guerre mondiale, dans une période où les conditions matérielles des journalistes s'étaient fortement dégradées. L'action des syndicats s'est développée et renforcée durant la première moitié du XXe siècle ${ }^{41}$. En effet, regroupant directeurs de presse, responsables de rédaction et journalistes, les associations professionnelles avaient certes permis d'instaurer les premières formes de solidarité entre collaborateurs de journaux, mais elles n'eurent jamais qu'un rôle secondaire et faiblement revendicatif. Quant aux mouvements syndicaux, ils ont entrepris de chasser les «amateurs » et se sont pleinement saisis de la condition de salarié du journaliste, obtenant de sérieuses améliorations matérielles et brisant ainsi «le mythe de la "grande famille" » de la presse $\mathrm{p}^{42}$. Si nous remarquons la présence de groupes à vocation généraliste (non présentés dans les tableaux précédents) tels que le Syndicat général des journalistes professionnels (1905) ou le Syndicat des journalistes (1918) qui ont joué un rôle important dans la structuration de la profession, nous sommes surtout frappés par la profusion d'associations spécialisées, renvoyant tantôt à des types d'activité professionnelle (chroniqueurs, critiques, sténographes, rédacteurs en chef, secrétaires de rédaction...), tantôt à des zones géographiques (régions, province, Paris...), tantôt encore à des thèmes abordés dans la presse (sport, justice, économie, agriculture et même alimentation ou industrie...). Cet extraordinaire fourmillement de syndicats et d'associations montre à quel point la construction professionnelle du journalisme est loin d'avoir été linéaire.

Parmi ces regroupements professionnels, nous trouvons des organisations formées par un certain nombre d'acteurs œuvrant dans les rubriques ou revues culturelles. Ceux-ci ont à ce point le sentiment de faire partie d'une «corporation» distincte qu'ils créent et/ou adhérent (à) des structures revendiquant une autonomie professionnelle. Là encore, ce mouvement n'est pas uniforme car les associations, dont les durées de vie ne sont jamais identiques, se constituent selon des axes différents: celui des activités rédactionnelles (courriéristes, critiques, bibliographes...), celui des zones géographiques et, en majorité, celui des thèmes abordés par la presse (la littérature, le théâtre, le cinéma et même, plus tard, la radio). Néanmoins, comparativement à d'autres spécialités, la culture rencontre une forte représentation puisque nous pouvons lui attribuer, après le premier conflit mondial (Annuaire daté de 1923), huit associations professionnelles et syndicales. Avec une égale constance dans le temps, ce sont surtout les critiques culturels qui constituent une force très présente dans les différentes éditions consultées. L'Association syndicale des critiques littéraires et bibliographes, le Syndicat de la critique parisienne et I'Association professionnelle et mutuelle de la critique dramatique et musicale sont régulièrement répertoriés ${ }^{43}$. La création de ces structures autour de la critique naît de la volonté de garder à distance certaines plumes signant dans les colonnes des journaux et possédant, en parallèle, une autre activité. Sur ce point, l'exemple du théâtre et de la constitution de ses critiques en groupe professionnel distinct, étudié par Sandrine Anglade ${ }^{44}$, est particulièrement éclairant.

En effet, dans le domaine du théâtre, quelques regroupements marquants peuvent être recensés comme I'Association professionnelle des courriéristes de théâtre des quotidiens de Paris (1911) et, surtout, I'Association syndicale professionnelle et mutuelle de la critique dramatique et musicale $(A S P M C D M)^{45}$. Cette dernière, qui se dote d'emblée du vocable «professionnel », fait prendre un vrai tournant à la critique dramatique (et musicale) car elle se présente comme un groupe à l'existence autonome, censé mettre à l'écart les enseignants, les auteurs de pièces ou les directeurs de théâtre exerçant aussi une activité de critique. L'ASPMCDM se compose de plusieurs personnalités connues dans le milieu du théâtre, mais elle tend aussi à regrouper progressivement des individus sans fortune, issus des classes moyennes, qui voient dans le journalisme naissant, non plus un complément d'activité, mais au contraire un véritable travail. Cette corporation se dote alors des moyens d'encadrer ses représentants en délivrant des cartes individuelles, prouvant l'appartenance au syndicat et établissant la spécificité de la pratique de la critique. Devenant une activité normée et autonome, cette dernière se généralise à l'ensemble de la culture dans la presse. Ainsi, à chaque fois qu'un nouveau thème apparaît, une association de critiques émerge,

\footnotetext{
${ }^{41}$ Ruellan, D., Les « Pro » du journalisme, op. cit., 1997, p. 30.

${ }^{42}$ Feyel, Gilles, La presse en France, op. cit., 1999, p. 160.

${ }^{43}$ Après la seconde guerre mondiale, alors que le nombre d'associations liées à la spécialité culturelle n'est plus que de six, ces trois organismes de critiques perdurent (voir l'Annuaire de 1949 non présenté ici).

${ }^{44}$ Anglade, S., Les journalistes, critiques de théâtre. Emergence et construction d'une identité professionnelle. Histoire de l'association de la critique dramatique et musicale (1899-1937), Université Paris 3, 1998.

45 Notons que dans les numéros consultés de l'Annuaire, le terme « syndical » n'apparaît pas. Plus tard, I'ASPMCDM changera de nom pour devenir le Syndicat professionnel de la critique dramatique et musical.
} 
telle l'Association de la critique cinématographique (voir I'Annuaire de 1934) ou I'Association de la critique de cinéma et de télévision (voir l'Annuaire de 1959 non présenté ici).

L'exemple de la constitution de ce mouvement professionnel et syndical nous paraît intéressant car il permet d'observer ce qui se passe chez les critiques en général, mais aussi au sein même de la spécialité culturelle. Parce qu'elle exerce sur les esprits une véritable attraction et qu'elle possède, à cette époque, un pouvoir certain dans I'univers des journaux, la critique va permettre à la spécialité toute entière de s'affirmer. Bénéficiant d'une représentation solide, elle va inciter les acteurs des rubriques et revues culturelles à créer des réseaux d'entraide et de soutien, qui vont durablement s'implanter dans l'espace journalistique. Ce rôle moteur des critiques est assuré par leur forte représentation au sein de la profession. L'exemple du théâtre l'illustre encore une fois: en 1908, les critiques sont au nombre de 186 sur les 256 journalistes français de théâtre ${ }^{46}$.

La création des premières associations professionnelles marque profondément la constitution de la spécialité culturelle en général. En effet, comme le remarque Denis Ruellan, ces lieux de cohésion professionnelle constituent des «matrices d'identités collectives ${ }^{47}$. Les regroupements de critiques tels que I'ASPMCDM, I'Association syndicale des critiques littéraires et bibliographes, le Syndicat de la critique parisienne, le syndicat de la presse artistique (fondé en 1899), constituent le socle des représentations des journalistes spécialisés dans les domaines culturels. Ils correspondent à l'incarnation symbolique à partir de laquelle ceux-ci vont prendre appui pour exister en tant que professionnels de la « chose écrite ».

Nous sommes même enclin à penser que les rédacteurs de critiques culturelles ont pu jouer un rôle déterminant dans l'affirmation non seulement de la spécialité culturelle, mais aussi de la profession toute entière. Sandrine Lévêque fait remarquer à propos des journalistes sociaux que "l'invention du social et les stratégies de mise en forme de cette catégorie dans l'espace journalistique offrent la possibilité d'apprécier comment un segment professionnel [...] participe à la construction d'un modèle d'excellence professionnelle, ici fondé sur la fonction critique, que commencent à revendiquer ceux qui s'engagent dans la lutte pour la reconnaissance de l'autonomie journalistique à cette époque ${ }^{48}$. Ainsi, à l'image des spécialistes de la question sociale, la volonté des acteurs de la critique culturelle d'instaurer leur approche comme principe premier du traitement journalistique, a pu contribuer à instaurer le journalisme en tant que profession autonome.

Deux éléments tirés d'un article de Gilles Feyel ${ }^{49}$, consacré aux origines identitaires des journalistes, renforcent cette indication. Tout d'abord, les rédacteurs de critiques sont impliqués dans les débats concernant l'évolution du métier. Parmi les dix huit associations françaises participant aux congrès internationaux des associations de presse, figure le Cercle de la critique musicale et dramatique (qui donnera l'ASPMCDM). Contrairement à d'autres regroupements professionnels issus d'autres spécialités, celui-ci a investi ces lieux de réflexion et d'échange, relatifs à la construction identitaire des journalistes. Ses représentants cherchent ainsi à faire valoir leur propre conception du métier de journaliste ainsi que des valeurs professionnelles conformes à leur engagement militant. Ensuite, le premier programme de formation au journalisme contient un enseignement entièrement consacré à la critique. En effet, lorsqu'en 1899, la première tentative de création d'école de journalisme voit le jour au sein du collège des Hautes Etudes Sociales, I'un des six cours dispensés s'intitule «critique dramatique et musicale ${ }^{50}$, signe manifeste de l'influence et de la légitimité de cette approche journalistique. Ainsi, ces rapides exemples tendent à nous indiquer que les professionnels de la critique ne se sont pas limités à constituer une communauté ayant sa propre identité et ses propres pratiques. Même si ce point mériterait sans doute une étude plus poussée, nous pouvons imaginer que les critiques culturels ont activement participé à I'affirmation de la profession toute entière.

Le détour socio-historique que nous avons proposé ici permet de mieux comprendre les ressorts du journalisme culturel. Celui-ci puise avant tout dans la dimension critique, voire politique, des premiers périodiques littéraires constituant alors un refuge de la liberté

\footnotetext{
46 Anglade, S., «La naissance du critique théâtral professionnel (1880-1930) 》, in Comédie-Française Les Cahiers, 1998, 29, p. 52

47 Ruellan, D., Les « pros » du journalisme..., op. cit., 1997, p. 11

${ }^{48}$ Lévêque, S., Les journalistes sociaux, op. cit., 2000, p. 18.

49 Feyel, G., "Aux origines de l'identité professionnelle des journalistes: les congrès internationaux des associations de la presse (1894-1914) 》 in Mathien, M., Rieffel, R., L'identité professionnelle des journalistes. Actes du colloque de Strasbourg, 25-26 novembre 1994, Strasbourg, Alphacom/Cuej, pp. 139-162.

${ }^{50}$ Les cinq autres enseignements sont les suivants : « grande actualité », 《 reportage à l'étranger », "étude de la presse française contemporaine », « étude de la presse étrangère » et «législation de la presse ». Cf. Feyel, G., ibid, p. 160.
} 
d'expression ${ }^{51}$. Au fil du temps, la critique va connaitre un certain nombre d'inflexions qui, comprises dans un mouvement plus général d'élargissement des méthodes de recueil et de traitement d'information, vont modifier durablement l'exercice du journalisme culturel. Parallèlement, ce sont les membres de la critique journalistique spécialisée dans les domaines culturels, qui vont permettre l'apparition d'une communauté professionnelle certes non homogène, mais suffisamment cohérente pour affirmer son existence dans l'espace journalistique.

L'influence de la critique ne se vérifie donc pas seulement en examinant le nombre de rubriques et de journaux culturels parus dans I'histoire de la presse. Elle se vérifie aussi lorsque nous suivons l'évolution professionnelle du journalisme culturel dont nous proposons ici une première étude que nous comptons compléter à l'avenir. La mise en lumière du rôle que cette spécialité a pu jouer dans la formation de la profession de journaliste en général nous semble, sur ce point, particulièrement heuristique. L'histoire de la presse culturelle témoigne du souci des gens de presse d'inscrire leur métier dans une fonction à la fois critique et politique, fondatrice d'un certain idéal professionnel. Depuis longtemps, écrire pour une gazette littéraire s'assimile tout autant à un exercice critique que politique et explique, finalement, qu'aujourd'hui encore l'information de presse culturelle soit pratiquée d'une manière « engagée ${ }^{52}$. Le tournant du XXe siècle est une étape historique décisive dans l'imaginaire collectif du journalisme naissant, qui tient pour référence la mission citoyenne que s'attribuent ses premiers représentants, et en particulier ceux qui officient dans le domaine culturel.

\footnotetext{
${ }^{51}$ Ceci tendait encore à se vérifier au cours des années quatre-vingt, comme l'illustre le cas des revues culturelles des pays de I'ex-Union Soviétique. Cf. Laurendeau, M., « Les revues culturelles soviétiques et la « glasnost » , in Charon, J.-M. (ss la dir. de), L'état des médias, La Découverte-Médiapouvoirs-CFPJ, Paris, 1991, pp. 94-95.

52 Paradoxalement, cet engagement peut permettre à certains journaux de trouver un positionnement éditorial original par rapport aux titres concurrents, voir sur ce point Blandin, C., Le Figaro littéraire. Vie d'un hebdomadaire politique et culturel (1946-1971), Nouveau Monde Editions, Coll. «Culture/Médias », Paris, 2010. Pour notre part, nous avions été conduit à remarquer l'emprise du traitement critique et engagée de l'information culturelle à travers l'étude des magazines culturels de marque, voir Spano, W., Des Marques à la page. Enjeux des pratiques journalistiques à travers l'étude des magazines culturels de marque, Université Stendhal, Grenoble 3, 2004.
} 